\title{
Editorial
}

\section{Acordada la estrategia española de seguridad y salud en el trabajo 2007-2012}

Un "gran instrumento" para luchar contra la siniestralidad laboral. Así cal ificó el Secretario General de Empleo, Antonio González, a la Estrategia Española de Seguridad y Salud en el Trabajo, que presentó el Ministro de Trabajo y Asuntos Sociales, Jesús Caldera, al Gobierno el pasado 29 de junio, tras recibir el visto bueno de la Comisión Nacional de Seguridad y Salud en el Trabajo.

Con su presentación se cumple el compromiso, por parte del Presidente del Gobierno en su acto de investidura, en abril de 2004, de elaborar un plan específico contra la siniestralidad.

La Estrategia Española de Seguridad y Salud en el Trabajo 2007-2012 constituye el instrumento para establecer el marco general de las políticas de prevención de riesgos laborales a corto y, sobre todo, a medio y largo plazo.

Con ella se pretende dotar de coherencia y racionalidad las actuaciones en materia de seguridad y salud en el trabajo desarrolladas por todos los actores relevantes en la prevención de riesgos laborales y, en definitiva, conseguir dos grandes objetivos: reducir la siniestralidad laboral y mejorar de forma continua los niveles de seguridad y salud.

El texto consensuado entre el Gobierno, las Organizaciones Empresariales y Sindicales y con la participación de las CCAA es el resultado de un largo proceso de diálogo que ha incluido un diagnóstico común de la situación de los riesgos laborales en España y la concreción de ocho objetivos operativos que se articulan al rededor de dos grandes líneas; una, la de medidas que tienen por objeto mejorar los sistemas de prevención en la empresa, a través del establecimiento de facilidades para el cumplimento normativo, en especial para las pyme y microempresas; también fomentando una mejora de la eficacia y calidad del sistema de prevención, optando por una efectiva integración preventiva. Así mismo se promueve la mayor implicación de los trabajadores y empresarios en la tarea cotidiana de la prevención.

La otra línea de estrategia pretende revitalizar las políticas públicas en esta materia, mediante una mejor coordinación e integración y el reforzamiento de las instituciones públicas dedicadas a la prevención, entre las que destaca la que se refiere a la reforma y potenciación del Instituto Nacional de Seguridad e Higiene en el Trabajo (INSHT). 
Además, dentro de este bloque merece especial relevancia el objetivo de "perfeccionar los sistemas de información e investigación", tareas en las que el INSHT ha de desarrollar una posición de liderazgo y coordinación, tanto en el ámbito nacional como en el de la cooperación con nuestros socios de la U.E.

En suma, una buena noticia: la de la finalización del proceso de acordar una estrategia nacional, pero con la que no se concluye el trabajo, sino que se comienza el despliegue de las medidas que lo componen.

Javier Pinilla García

Consejero Técnico de Investigación y Promoción del Instituto Nacional de Seguridad e Higiene del Trabajo (INSHT). 